\title{
ARENIZAÇÃO, SILVICULTURA E POLÍTICAS AMBIENTAIS NO SUDOESTE DO RIO GRANDE DO SUL
}

\author{
JOSÉ CARLOS CORRÊA RIBEIRO ${ }^{1}$ \\ ROBERTO VERDUM ${ }^{2}$ \\ Universidade Federal do Rio Grande do Sul
}

\section{Introdução}

Arenização e silvicultura consistem numa problematização que perpassa diversos segmentos da sociedade, entre comunidades locais de agricultores e pecuaristas, técnicos, cientistas e políticos. Desde a década de setenta do século XX, esse tema vem ocupando as pautas das questões ambientais referentes à região Sudoeste do Rio Grande do Sul. São, portanto, temas conexos, na medida em que a arenização é apontada como principal processo de degradação ambiental da região, enquanto a silvicultura foi privilegiada como solução nas políticas ambientais, tanto públicas como nas parcerias do público-privado.

O presente texto consiste em uma análise crítica sobre as políticas ambientais voltadas para a região Sudoeste do Rio Grande do Sul, com ênfase para a arenização e a silvicultura. Pretende-se demonstrar que essas políticas ambientais, iniciadas no contexto da crise socioecológica da década de setenta do século XX, apresentam dimensões institucionais transescalares. Do contexto global, passando pelas políticas nacionais, regionais, municipais, chegando ao contexto da localidade da Vila Kraemer, município de São Francisco de Assis/RS (Figura 1), as políticas ambientais externas passam a integrar as práticas locais de conservação do solo nos areais.

Também incluímos, dentre as questões aqui debatidas, a dificultosa inclusão do viés social e do imponderável humano nas políticas públicas

${ }^{1}$ Doutorando do PPG em Geografia/IG/UFRGS

${ }^{2}$ Professor Doutor do Departamento de Geografia e do PPG em Geografia/IG/UFRGS 
em relação à arenização enquanto questão ambiental. Os dados empíricos, obtidos em campo, corroboram essa constatação e evidenciam que as concepções que os Homens fazem do ambiente, cultural e ideologicamente influenciadas, são decisivas na adoção das práticas de conservação do meio (solo, água, vegetação, ar, etc.).

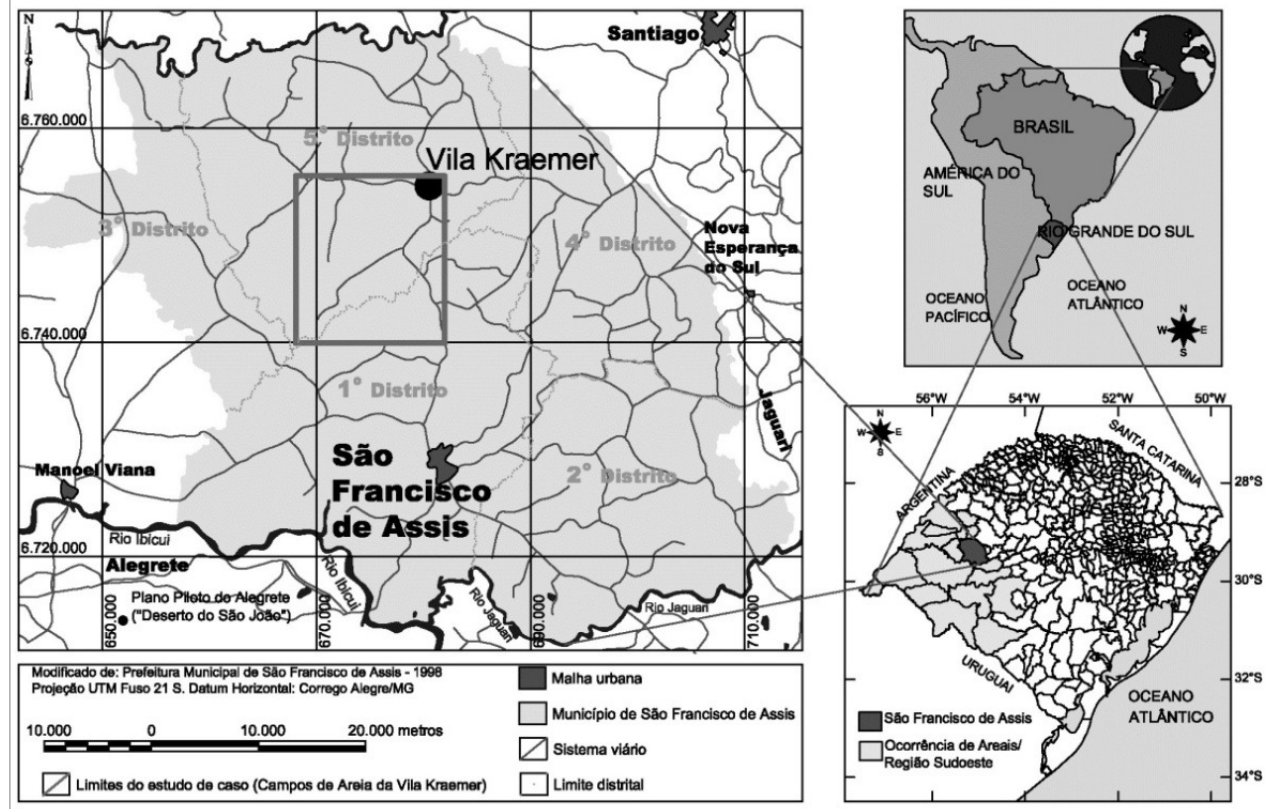

Figura 1: Mapa de localização

\section{Estudos pioneiros sobre arenização no sudoeste do Rio Grande do Sul}

Os areais constituem depósitos areníticos recentes, pouco consolidados ou arenosos não consolidados, com cobertura vegetal escassa ou inexistente e em constante retrabalhamento por agentes climáticos. A gênese dessas manchas arenosas está relacionada à fragilidade da paisagem em sua totalidade, devido à susceptibilidade das unidades litológicas ao processo de arenização (SUERTEGARAY, 1996). 
A arenização, por seu turno, corresponde ao processo de formação dos areais. Esse processo morfogenético é visto como "um dos processos mais intensos de degradação ambiental que ocorrem na região da fronteira oeste do Estado" (BERTÊ, 2004), atingindo áreas nos municípios de Alegrete, Cacequí, Itaqui, Maçambará, Manuel Viana, , Rosário do Sul, São Borja, São Francisco de Assis e Unistalda. Ao todo, são 3.663 hectares de manchas arenosas e 1.600 hectares de focos de arenização (SUERTEGARAY, GUASSELI e VERDUM, 2001).

Segundo Ab'Saber (1995) os trabalhos pioneiros que contribuíram para a divulgação da questão dos areais do sudoeste gaúcho foram realizados por Möller e outros (1975) - feitos pelos técnicos da Superintendência do Desenvolvimento da Região Sul (SUDESUL), com a denominação de "Diagnóstico sobre a presença de areia na região sudoeste do Rio Grande do Sul" - e o trabalho de Cordeiro e Soares (1977), resultante de uma longa investigação feita por pesquisadores do Instituto Brasileiro de Geografia e Estatística (IBGE), sob o título de "A erosão nos solos arenosos da região sudoeste do Rio Grande do Sul".

A bibliografia subsequente sobre a arenização é composta pelos trabalhos de Souto (1985), Suertegaray (1987) e pelo trabalho de Gomes, Carvalho e Barboza (1990).

O trabalho do Agrônomo Souto (1985), um dos responsáveis pelo "Plano Piloto no Deserto de São João/Alegrete" (1977-1984), se caracteriza pelo alarmismo em relação à suposta "desertificação", pela ênfase à deflação eólica e sua mitigação, mediante o plantio de eucalipto e, ainda, pela responsabilização da ação humana na formação dos "desertos".

Um importante contraponto para a concepção a respeito dos areais utilizada por Souto (1985) é o trabalho de Suertegaray (1987) que desmistifica e relativiza algumas ideias propaladas na época, a exemplo da noção de "desertificação" e sua gênese humana. Em oposição à ideia de "deserto", a autora resgatou topônimos locais como "Areal" e "Rincão do Areal", onde a ocorrência dos areais tem um grau de antiguidade maior, não tendo 'vínculos' com a expansão da agricultura mecanizada e os usos inadequados recentes dos solos regionais (AB'SABER, 1995).

O trabalho de Gomes, Carvalho e Barboza (1990) tinha por finalidade o "estudo de fenômenos de degradação do meio natural em áreas do município de Alegrete/RS". Esse trabalho, liderado por Gomes, já revelava alguma preocupação com relação à percepção dos agricultores sobre os problemas ambientais e mostra que a arenização, na ótica dos 
agricultores, não é o principal problema, pois, "ocorrem outros que afetam as terras lavradas e que também acarretam preocupação para lavradores e criadores. São eles, além das manchas de areia, os ravinamentos intensos, as inundações das várzeas e os afloramentos rochosos" (GOMES, CARVALHO e BARBOZA, 1990, pag.243). As autoras preconizam, ainda, a interferência humana como forma de controle desses processos e a determinação dos "pontos do sistema onde uma intervenção oferece a maior probabilidade de sucesso e com menor custo" (GOMES, CARVALHO e BARBOZA, 1990, pag. 243). Essa reflexão corrobora a necessidade de uma política de gestão ambiental que inclua não somente técnicos e cientistas, mas agricultores e pecuaristas, pois, somente assim, se encontrará uma alternativa exequível de acordo com a realidade local.

\section{Arenização e propostas de recuperação: do global ao local}

A partir da década de 1970, o Sudoeste do Rio Grande do Sul passou a ser visto como região sujeita à "desertificação" (sic), em razão, principalmente, dos artigos científicos e reportagens que criam um clima de alarmismo em torno da arenização. Os pesquisadores Cordeiro e Soares (1977), perspicazmente, comentavam esses alarmismos:

A propalada 'desertificação' dos campos do sudoeste do Rio Grande do sul pela imprensa, que informa terem sido transformadas 'extensas áreas' em 'minidesertos', é mais uma forma de expressão do que uma divulgação da realidade: as áreas tornadas 'mini-desertos', segundo o noticiário dos jornais, não passam de uma centena de manchas de areia, a mais extensa delas até agora medida não passando de 200 hectares (CORDEIRO; SOARES, 1977, P. 142).

Entretanto, a "desertificação", acompanhada da ideia desse fenômeno como: "fruto da irracionalidade do uso do solo", continuou a ser uma das principais notícias a respeito da região, assim como a necessidade de "combate aos desertos" mediante o florestamento, conforme exemplificam os trechos a seguir:

Às margens da BR 293, a 35 quilômetros de, um deserto de areias vermelhas no meio do pampa verde surge como miragem. São quase 10 hectares de areia vermelha, com dunas e formações curiosas provocadas pelo vento, numa 
paisagem realmente de deserto. (...) Ao entardecer, provocam imagens semelhantes as do ambiente em que se desenvolve a guerra do golfo. (...) (MATZENBACHER,1991, p. 07)

A Secretaria da Agricultura mantém, desde o ano passado, um convênio com a SUDESUL e a prefeitura de Alegrete visando reverter esse quadro e, principalmente, conscientizar os produtores da necessidade de usarem a terra de forma mais racional. (...) Além disso, o secretário Marcos Palombini, ciente da gravidade do problema, manteve contato com a equipe técnica de engenheiros florestais da Riocell na busca de estudarem alternativas de aproveitamento da terra já desertificada. (SOMMER, 1990, p. 12).

Essa preocupação chega ao Rio Grande do Sul no contexto do que Vieira, Berckes e Seixas (2005) chamaram de "crise socioecológica da década de setenta", após a Conferência das Nações Unidas para o Meio Ambiente, realizada em Estocolmo em 1972, e, em 1977, com a realização, pelo Programa das Nações Unidas para o Meio Ambiente (PNUMA), de uma conferência em Nairobi/Quênia.

O tema da desertificação vem ao debate quando a Conferência das Nações Unidas sobre Desertificação (CONUD) reconhece a desertificação como "um problema ambiental com elevado custo humano, social e econômico" (SUERTEGARAY, 1996). A partir daí, uma série de formulações apontam o Homem como principal agente causador dos desertos, em função do manejo inadequado e do desrespeito às aptidões de uso do solo.

Dentre as publicações científicas, de âmbito regional, que mais contribuíram para o alarmismo em torno da "desertificação", e para o estigma negativo do Homem do campo, tem destaque o já comentado trabalho de Souto (1985) que atribuía origem humana ao processo de "desertificação" no sudoeste do Rio Grande do Sul, apontando o superpastoreio e a mecanização das lavouras como ações antrópicas responsáveis.

Contribuindo para essa noção, a década de 1970 é marcada, local e regionalmente, pela modernização da agricultura e pela expansão da área dedicada aos cultivos. Nesse contexto, a chamada Revolução Verde trouxe consigo os tratores, o crédito rural e, atraído pela ciranda financeira, o agricultor arrendatário, sobretudo nas áreas de campo do Pampa. 
$\mathrm{O}$ aumento das áreas cultivadas com soja em sistema tradicional de plantio com o uso de arado para revolver o solo a cada plantio, na região, atingiu seu ápice durante a década de 1980, entrando em declínio entre 1985 e 1996 (VERDUM, 2004; MÓSENA, 2006). Esse declínio ocorreu por duas razões: a redução do valor pago pela soja no mercado internacional, a redução dos incentivos governamentais e, finalmente, o rápido esgotamento dos solos, essencialmente arenosos, que eram reservados ao cultivo (SUERTEGARAY, GUASSELI e VERDUM, 2001).

Embora a gênese dos areais tenha origem natural, supõe-se que a intensificação do uso do solo, associada à ausência de práticas de conservação ao final do período de arrendamento, teria promovido a intensificação dos processos morfogenéticos (arenização, ravinamentos e voçorocamentos), alimentando a razão dos que propalavam esse processo como sendo a "desertificação".

Ainda na década de 1970, surgem as primeiras propostas de "recuperação de desertos". Essas propostas tiveram início através da Secretaria de Agricultura do Estado do Rio Grande do Sul, com o Plano Piloto de Alegrete, que consistia na instalação de quebra-ventos e plantio de espécies arbóreas e arbustivas, leguminosas e gramíneas. Desse plano piloto, resultou a conclusão de que a espécie que melhor se desenvolvia sobre os areais era o eucalipto (SOUTO, 1985).

No âmbito federal, o plantio de eucalipto ganha destaque entre as políticas ambientais com o lançamento do "Plano Nacional de Celulose e Papel" (1967). De acordo com Suertegaray (1996), esses incentivos vieram também através das agências financiadoras internacionais, como o Banco Mundial, que incentivava o plantio de eucalipto. Mas o programa federal brasileiro diminui seus incentivos fiscai, a partir de 1987.

Em 1990, surge o projeto FLORAM (INSTITUTO DE ESTUDOS AVANÇADOS, 1990), estudo em que se propõe o plantio de eucalipto, com o pretexto de diminuir os níveis de dióxido de carbono na atmosfera e incorporar áreas desmatadas ou pobres, do ponto de vista agrícola, ao processo produtivo (SUERTEGARAY, 1998).

Entre o final da década de 1980 e o início da década de 1990, desta vez por iniciativa privada (RIOCELL S/A e TANAC S/A), intermediada pelo Governo do Estado do Rio Grande do Sul, surgem tentativas de "recuperação dos areais", mediante o plantio de eucalipto e acácia negra com vistas à industrialização da região. O convênio, firmado entre Secretaria da Agricultura e empresas florestadoras, consistiu na 
continuidade do Plano Piloto do Alegrete. Desse modo, era divulgada a silvicultura como forma de combate aos "desertos". Além do experimento realizado no "deserto do São João", em Alegrete, mudas de eucalipto eram distribuídas aos agricultores pela Secretaria da Agricultura, com o apoio da Associação Riograndense de Empreendimentos de Assistência Técnica de Extensão Rural - EMATER.

É importante, ainda, salientar que as iniciativas de combate à "desertificação" carregam um forte viés partidário, haja vista que as propostas para a retomada do Plano Piloto do Alegrete são associadas às diretrizes de desenvolvimento do Partido do Movimento Democrático Brasileiro (PMDB), a exemplo do Governador Pedro Simon (março de 1987 até abril de 1990) e do Secretário da Agricultura Marcos Palombini (no mesmo período).

Passadas mais de três décadas da propalada "desertificação", um novo empreendimento florestal - pela sueco-finlandesa Stora Enso - é atraído para o estado, novamente pelas diretrizes desenvolvimentistas do PMDB, na pessoa do então Governador Germano Rigotto (janeiro de 2003 até janeiro de 2007). O empreendimento da Stora Enso, cujo plantio é realizado na região pela subsidiária Derflim Agropecuária Ltda., previa, em 2007, o plantio de 100 mil hectares de eucalipto, numa região de interesse que abarcava onze municípios: Alegrete, Cacequi, Itaqui, Maçambará, Manoel Viana, Rosário do Sul, São Borja, São Francisco de Assis, São Gabriel, São Vicente do Sul e Unistalda (SILVICONSULT, 2007). Embora o discurso de combate aos "desertos" tenha perdido espaço na imprensa, principalmente em função da desconstrução dos mitos a respeito do tema, os municípios contemplados pela silvicultura são, praticamente, os mesmos de ocorrência de areais.

Com a chegada da Stora Enso na região, em 2007, o debate ambiental atual é marcado pela oposição de dois discursos opostos. De um lado, a visão agroeconômica defende a implantação de projetos da monocultura de eucalipto para a utilização industrial na região da Campanha. De outro lado, a visão conservacionista busca a valorização das paisagens naturais do "bioma Pampa" e a desmistificação dos areais.

Quanto à corrente conservacionista, cabe salientar que recentes descobertas científicas valorizam os areais como relictos de climas pretéritos; como ambientes de espécies animais e vegetais endêmicas; e, enfim, por toda a riqueza em termos científicos e pela sua função ecológica. Exemplifica essa nova geração Pires da Silva (2008), que revela, em suas pesquisas nos areais, espécies de fauna com respostas adaptativas 
peculiares e Freitas (2010), com seus estudos sobre aspectos florísticos adaptativos aos solos arenosos do Sudoeste do Rio Grande do Sul.

Entre as consequências dessa ruptura de paradigma, técnicos e entidades envolvidas na elaboração do Zoneamento Ambiental para a Silvicultura (BERED; FERRARO; PAGEL, 2007, pag. 38) preconizam a "conservação dos areais mais antigos e ou estabilizados representativos" e também de "seu entorno, em uma Área de Proteção Permanente (APP) de 150 metros". Elaborada pelo corpo técnico da Fundação Estadual de Proteção Ambiental (FEPAM) e da Fundação Zoobotânica do Rio Grande do Sul (FZB), a primeira versão do Zoneamento Ambiental para a Silvicultura causou polêmica e foi considerada demasiado restritiva pelos "investidores estrangeiros". Foi, justamente a fácil aquisição das desvalorizadas terras de solos arenosos e com a presença de areais, o condicionante ambiental e econômico que atraiu tais "investidores".

Desse modo, as políticas ambientais públicas que, ao longo de quatro décadas, prescreviam o combate aos areais, atualmente prescrevem a sua conservação. Pode-se afirmar que a política ambiental acompanhou, ao menos parcial e momentaneamente, as mudanças de paradigma a respeito da arenização.

\section{Arenização, imaginário e práticas locais de conservação do solo}

Para os agricultores e os pecuaristas, os areais (também as ravinas e voçorocas) representam, em certos casos, maior ou menor dificuldade para a realização de atividades ligadas ao uso do solo. Sua dinâmica de formação, relacionada ao retrabalhamento por processos hídricos e eólicos, acarreta dificuldade na fixação da vegetação. Diante dessa fragilidade da paisagem, verifica-se a adoção de técnicas de manejo e gestão desses solos frágeis por parte de técnicos, agricultores e pecuaristas locais. Os dados empíricos observados nos areais do município de São Francisco de Assis e, em especial, no distrito da Vila Kraemer, evidenciam uma forte relação entre os esquemas de percepção e a concepção dos atores locais (agricultores, técnicos, etc.) com os respectivos modos como eles gerenciam o solo em suas propriedades.

Com a redução das perniciosas práticas de uso do solo adotadas no contexto da "Revolução Verde", na paisagem no distrito da Vila Kraemer, passam a predominar pastagens exóticas, introduzidas para evitar a exposição das "areias vivas" e permitir o aumento da lotação animal, além 
dos plantios de soja e aveia em sucessão. Além dessas medidas, observa-se a ampla difusão do plantio de "capões" de eucalipto, com a função de quebra-vento.

O estudo de caso realizado ressalva que as práticas locais de gestão do solo, em seu conjunto, são intimamente relacionadas à percepção acerca dos agentes climáticos (ação eólica e hídrica), envolvidos nos processos morfogenéticos, incluindo não somente a arenização, mas os ravinamentos e voçorocamentos.

Ainda que existam diferenças entre a percepção dos pesquisadores e dos moradores do campo, é bastante comum a percepção de que a arenização é um processo natural e bastante antigo. Acredita-se, entretanto, que o processo pode ser intensificado pela ação humana, tanto pela agricultura quanto pela pecuária, especialmente quando não são realizadas práticas de conservação dos solos.

Igualmente é comum a noção de que a arenização, ampliando-se indefinidamente, consiste em um problema humano que pode acarretar na formação de "desertos". Nesse sistema de concepção, portanto, os areais são formas conhecidas e associadas a uma dinâmica natural, enquanto os imaginados e temidos "desertos" se associam a perniciosa ação humana (sic). Nota-se uma mescla de ideologias internalizadas e percepções empíricas formatando as representações e os imaginários a respeito dos areais.

Outra ideia bastante comum, entre agricultores e citadinos, é a referência à década de 1970 como o período de maior intensificação dos processos morfogenéticos (arenização, ravinamentos e voçorocamentos). A maioria dos respondentes da pesquisa atribuiu a intensificação dos processos à mecanização da agricultura no contexto da "Revolução Verde". Alguns responsabilizam uma grande enchente, ocorrida no ano de 1973, pelos ravinamentos e voçorocamentos.

Quanto aos agentes climáticos que participam nos processos morfogenéticos, os agricultores/pecuaristas identificam nitidamente a participação de dois agentes climáticos - a água de torrentes e o vento, atuando em fases sequenciais e associadas. Também se destaca o pisoteio do gado como agente atuante na fragilização do solo e a consequente exposição aos agentes climáticos.

Esses agentes climáticos são associados pelos agricultores a duas formas encontradas na natureza: as ravinas e as voçorocas, associadas ao escoamento concentrado das águas torrenciais; e os areais, associados ao 
trabalho de varredura pelo vento de áreas desprovidas de cobertura vegetal (deflação). Acreditam os agricultores e pecuaristas que a água e seus efeitos, materializados na forma de ravinas e voçorocas, não podem ser controlados tão facilmente. $\mathrm{O}$ mesmo não se pensa em relação ao vento e seus efeitos, independente da denominação que receba (areal, mancha de areia, campos de areia, desertos, ilhas de desertos, desertinhos).

Desse modo, a maioria dos agricultores/pecuaristas concentra seus esforços de combate aos areais com a introdução de dispositivos que evitem a ação do vento. Mitigam-se as consequências do pisoteio do gado, com o manejo de forrageiras (Capim-Marandu: Brachiaria brizantha e Capim-Pangola: Digitaria decumbens), e reduz-se a velocidade dos ventos com o plantio de capões de eucalipto nos focos iniciais de arenização. A aplicação conjunta desses dois dispositivos, "quebra-vento" e forrageiras, recebe entre os nativos o nome de "sitiamento" ou "bordadura" e são observados em toda a região, como nos exemplos de São Francisco de Assis (Figura 2), Manoel Viana (Figura 3) e Alegrete (Figura 4).

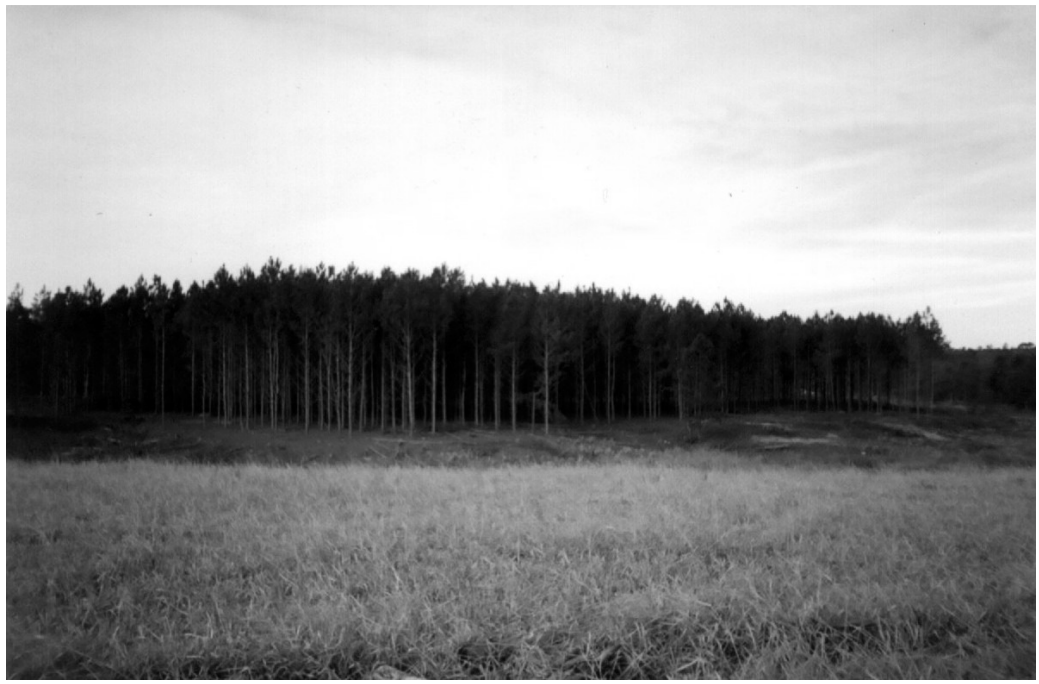

Figura 2 - Areal totalmente recoberto com pinus e brachiária em São Francisco de Assis (os autores, 2007) 


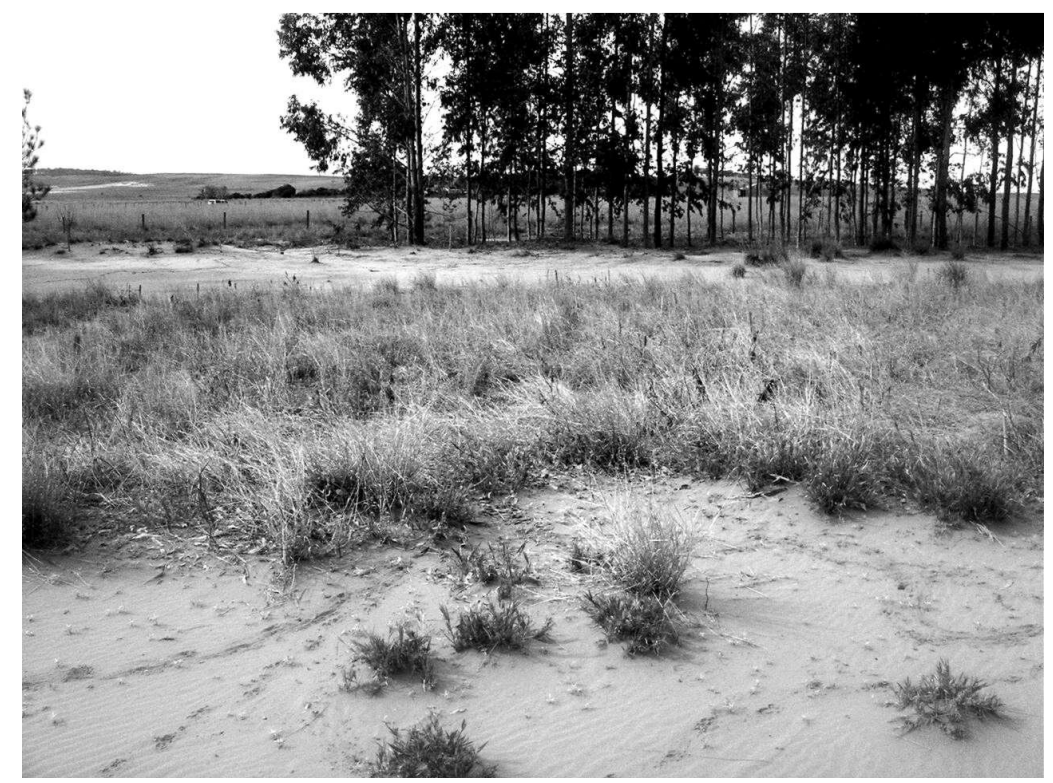

Figura 3 - Sitiamento de areal com eucalipto em Manoel Viana (os autores, 2007)

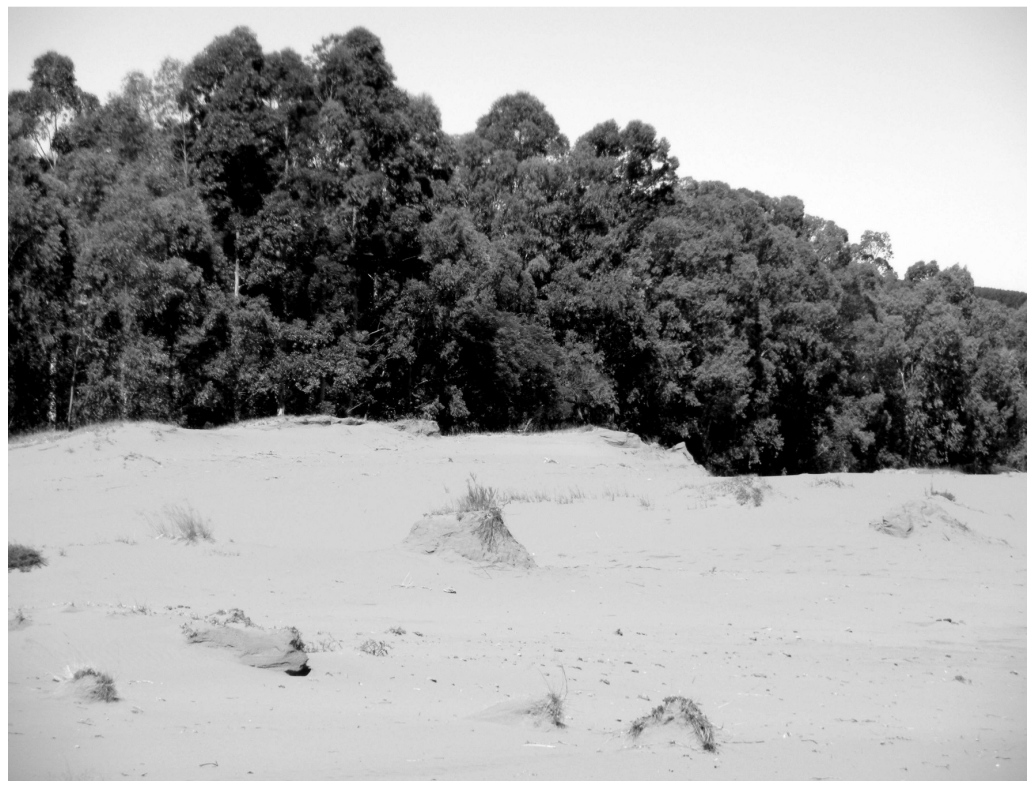

Figura 4 - Sitiamento de areal com eucalipto em Alegrete (os autores, 2013) 
Essas ações de desvalorização dos areais e a valorização das espécies exóticas, como o eucalipto, corroboram a noção de que "os conceitos culturais de natureza são diferentes das concepções científicas sobre função ecológica da paisagem" (NASSAUER, 1995, p. 234). Os dados coletados em campo permitem constatar que é generalizada a concepção de que os areais não representam a natureza e que a as pastagens e as árvores exóticas, sim, representam a natureza. A arenização surge como uma imagem de devastação da natureza, a despeito dos recentes esforços dos cientistas em demonstrar a diversidade geobiológica que se debruça nos areais.

Cabe, ainda, destacar a parcimoniosa aceitação da empresa Stora Enso. Essa empresa, em 2007, adquiriu na localidade da Vila Kraemer 3.744 hectares e a instalação de monoculturas de árvores geneticamente clonadas é percebida nos relatos dos atuais moradores da Vila Kraemer como um grande benefício "em defesa da natureza". Quanto à repercussão local a respeito do Zoneamento Ambiental para a Silvicultura, manifestações de estranhamento e, até mesmo de indignação, foram observadas no estudo de caso e ilustram esse paradoxo que coloca, de um lado, os técnicos de órgãos ambientais do Governo do Estado do Rio Grande do Sul, interessados na conservação da natureza e, de outro, a empresa florestadora e os agricultores/pecuaristas, interessados no "lucro" de suas atividades, nesses solos considerados frágeis e pouco férteis.

A expressão maior da transformação da paisagem representada pela instalação da silvicultura industrial no Pampa sul-rio-grandense é a consequente cedência do território para interesses majoritariamente externos. Isso implica na "controversa noção de urbanização do campo que quer significar a transformação também do conteúdo material do território" (SANTOS, 1997, p. 203). A esse processo de criação de uma "segunda natureza", se junta essa revolução tecnoagrícola do mundo atual. A chegada da empresa Stora Enso surge no bojo dessa revolução tecnoagrícola, transformando a natureza em uma segunda natureza e cria uma tecnosfera. De acordo com Santos:

Ao mesmo tempo em que se instala uma tecnosfera dependente da ciência e da tecnologia, cria-se, paralelamente, e com as mesmas bases, uma psicosfera. A psicosfera, reino das ideias, crenças, paixões e lugar da produção de um sentido, também faz parte desse meio ambiente, desse entorno da vida, fornecendo regras à racionalidade ou estimulando o imaginário". (SANTOS, 1997, p. 204). 
A psicosfera, em curtas palavras, serve de substrato ideológico para a fixação da tecnosfera, da segunda natureza, pois

\begin{abstract}
Essa psicosfera consolida a base social da técnica e a adequação comportamental à interação moderna entre tecnologia e valores sociais (...) a psicosfera apóia, acompanha e, por vezes, antecede a expansão do meio técnico-cientifico (RIBEIRO, 1991, p. 48 apud SANTOS, 1997, p. 48).
\end{abstract}

Toda a base tecnológica e científica de conhecimento, necessária para a instalação da silvicultura forja os moldes do senso comum (a psicoesfera). Essa base científica e tecnológica está presente nas formulações científicas, nos experimentos de contenção de areais como Plano Piloto do Alegrete, nas orientações de técnicos da EMATER, etc. A base científica é, ainda, imitada em sua técnica pelos leigos, como no caso das experiências realizadas pelos agricultores e pecuaristas da Vila Kraemer.

No estudo de caso realizado na Vila Kraemer, foram investigadas as relações de codeterminação entre o imaginário e as transformações na paisagem. Em outras palavras, foram estudadas as relações entre a psicosfera e a tecnosfera.

Essa interação apresenta dimensões que transcendem os limites do local, pois "ambas - tecnosfera e psicosfera - são locais, mas constituem o produto de uma sociedade bem mais ampla do que o lugar. Suas inspirações e suas leis têm dimensões mais amplas e mais complexas" (SANTOS, 1997, p. 204). Elementos da criação da psicosfera estão presentes, por exemplo, na adoção da palavra "deserto". A carga semântica dessa palavra perpassou as esferas global (no âmbito das Nações Unidas), regional (governo do estado), municipal (São Francisco de Asssis) e local (na Vila Kraemer). O mesmo ocorre com relação às proposições de plantio de árvores sobre esses areais que surgem de fora para dentro como uma solução vendida para um problema inventado. Acompanhando esse fluxo de ideologias, do global ao local, estão as políticas ambientais públicas e privadas voltadas para a arenização e a silvicultura.

Essa relação entre o local e o global (Figura 5) consiste no que Vieira, Berckes e Seixas (2005) chamam de "conexões institucionais transescalares", ou como "conjuntos de sistemas imbricados uns nos outros e organizados segundo níveis hierárquicos de complexidade, do local ao 
global, passando pelos níveis municipal, intermunicipal, estadual, nacional e regional".

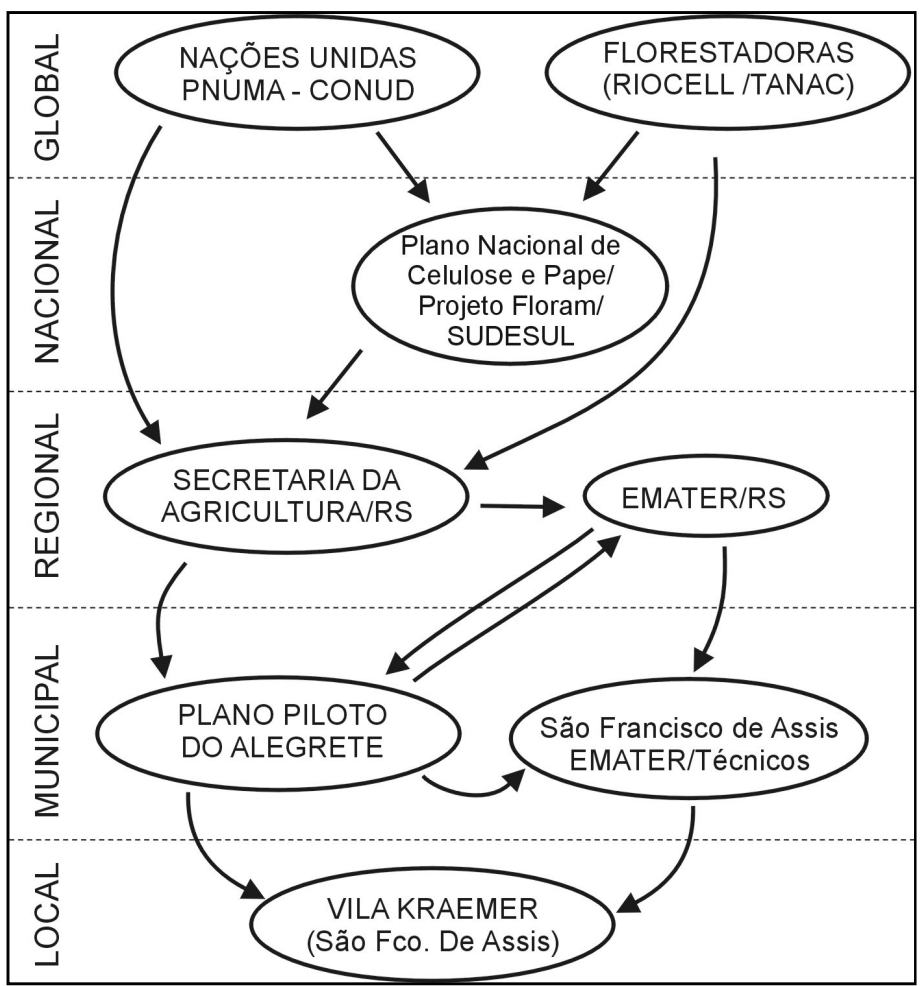

Figura 5 - Conexões institucionais das políticas ambientais para a arenização (os autores).

\section{A arenização, abordagem ambiental e desafios epistemológicos}

A questão ambiental, que envolve a arenização (como "problema") e a silvicultura (como "solução do problema"), emerge no contexto da já descrita "crise socioecológica da década de setenta do século XX (...)quando um conjunto de problemas interdependentes passa a ser associado à degradação crescente das bases biofísicas de sobrevivência da espécie humana" (VIEIRA, BERCKES e SEIXAS, 2005). Essa 
constatação, de acordo com os autores, "abriu pistas para reflexão sobre a dimensão humana das mudanças ambientais e reavaliação das estratégias de desenvolvimento". Esses autores acrescentam que "a destruição dos ecossistemas e das culturas humanas colocam a sociedade frente a desafios inéditos" com implicações "epistemológicas, éticas e políticas". De fato, o amplo debate existente sobre arenização e silvicultura corrobora a ideia de que essas questões ambientais consistem em objetos de pesquisa, não somente naturais, mas políticos, complexos e com um forte viés social. Dar conta dessa questão requer uma revisão nos paradigmas que compõem as políticas de conhecimento e gestão da natureza, partindo de uma postura que inclua a sociedade não como elemento, mas como sujeito que atua e interfere na dinâmica da natureza.

O desafio epistemológico para o entendimento de "como as sociedades lidam com as inter-relações entre as dinâmicas naturais e sociais deve levar em conta a força de inércia do paradigma científico analítico-reducionista" (VON BERTALANFFY, 1968 apud VIEIRA, BERCKES e SEIXAS, 2005, pag. 13)". Tal paradigma, de influência iluminista-positivista, acarreta na ilusão de que os aspectos relativos às humanidades acontecem fora da natureza.

Velho (2001) comenta a separação ocorrida no século XVIII e radicalizada no século XIX entre as ciências sociais, ou do espírito (Geisteswissenschaften) e as ciências naturais (Naturwissenschaften). Os objetos da natureza seriam explicados pelo método indutivo-dedutivo, enquanto as ciências sociais deveriam se ocupar de objetos que pudessem ser interpretados subjetivamente (VELHO, 2001).

Latour, Schwartz e Charvolin (1998) também denunciam a divisão moderna do saber em dois ramos: o político, dos objetos de direito, dos humanos e; o científico, dos objetos de fato, da natureza. $\mathrm{O}$ paradigma moderno separa a realidade não em função da essência dos objetos, mas em função de divisões coletivas e metodológicas, arbitrariamente. Provém dessa divisão a dificuldade em estudar a interação sociedade/natureza.

O resultado dessa dicotomia é que, sob a chancela do ambiente, temas importantes para a sociedade não a incluem de modo igual. Nas questões ambientais, a ênfase naturalista conduz à elaboração de políticas governamentais, onde o viés social é, não raro, negligenciado.

No presente caso, em diversas reportagens e pesquisas sobre o fenômeno da formação das "manchas de areias", "dos desertos", da "desertificação" e da "arenização" no sudoeste do Rio Grande do Sul, ao 
longo de seus 40 anos de problematização, o Homem do campo vem sendo apontado como responsável pela degradação dos solos, recaindo-lhe um forte estigma de devastador da natureza. Mesmo com a recente tendência, que retoma a gênese natural dos areais e os valoriza por suas funções ecológicas, o Homem do campo tem sido incluído como elemento, não como sujeito que opina e participa das decisões ambientais. Há, pois, uma demanda crescente pelo envolvimento ativo das populações nas decisões ambientais, que reflete a verdade de que "os planejadores não podem e não vão fazer o suficiente para proteger o valor de nossas paisagens e os modos de vida associados a estas". (GOLD e BURGESS, 1982: 1-5 apud BLEY, 1996).

Nesse sentido, de não negligenciar nenhum dos aspectos da realidade, Mendonça (2009) preconiza uma "Geografia socioambiental" ancorada na concepção de que talvez "o maior ponto de relevância epistemológica para a Geografia esteja na atitude fenomenológica de não considerar nem a Natureza (matéria da experiência) nem o Homem (corpo que percebe) como fundantes" (MONTEIRO, 1984, p. 26). De modo semelhante, Velho (2001) preconiza a atitude fenomenológica no entendimento das questões ambientais contemporâneas e acrescenta a importância das relações entre a mente humana e a ecologia. Seus argumentos são motivados pela re-publicação da obra Steps to an Ecology of Mind de Bateson (2000), originalmente publicada em 1972 e que tinha, na orientação fenomenológica, a postura para abordagem das relações entre a mente humana e a ecologia. Velho é também motivado pela recente publicação de The perception of the Environment: Essays in livelihood, Dwelling na Skill de Tim Ingold (2000), a qual retoma as preocupações de Bateson.

Em meio a esse despertar para um novo paradigma, surge, no contexto das Nações Unidas, aquele que pretendia ser um marco das ciências naturais e sociais - o programa Homem e Biosfera - MAB (UNESCO, 1981). Esse programa "pretendia contribuir com uma base racional para a utilização e conservação dos recursos da biosfera e para a melhoria das relações entre o Homem e seu ambiente" (CASTELLO, 1996). Uma importante contribuição, no âmbito dos programas MAB, foi o trabalho de WHYTE (1977) intitulado Guidelines for field studies in environmental perception. Esse trabalho consagra a percepção ambiental como ferramenta de trabalho importantíssima a ser aplicada na recuperação de áreas degradadas e projetos urbanísticos. Arquitetos e urbanistas brasileiros fizeram ampla utilização dessa metodologia no projeto urbano. 
Os dados obtidos em campo realizado em São Francisco de Assis evidenciam uma forte relação entre a percepção ambiental dos atores sociais (agricultores, técnicos, etc.) e os respectivos modos como esses atores gerenciam a natureza, incluindo os areais, em suas propriedades. Observou-se, nesse estudo de caso, a existência de um conjunto de práticas de conservação do solo, em que a concepção local de natureza e as preferências ambientais e paisagísticas, cultural e ideologicamente construídas, são decisivas, diferindo-se em muito das concepções científicas e das funções ecológicas da paisagem. Isso corrobora a importância das dimensões subjetivas, do imponderável humano, envolvidas na gestão da natureza. Nesse sentido, a percepção ambiental oferece um paradigma das relações Homem-meio no qual a concepção humana do ambiente, individual e coletiva, é considerada como a principal força transformadora do meio através da ação de escolhas e comportamentos humanos e "a percepção humana é considerada tão fundamental que se transforma no principal ponto de partida para toda a análise da relação homem-meio" (WHYTE, 1977).

\section{Considerações finais}

Face aos argumentos aqui expostos, cabe destacar a necessidade da valorização de bases teórico-metodológicas capazes de subsidiar uma política de conhecimento e gestão da paisagem (e dos areais) onde o natural e o social sejam elementos imbricados. Nessa busca, algumas reflexões ainda precisam ser realizadas com maior profundidade a respeito das quatro décadas de estudos da arenização - Qual a ênfase predominantemente adotada nesses estudos? Qual o impacto das formulações científicas no imaginário e nas ações dos atores sociais? Quais as suas implicações nas políticas públicas em relação aos areais? Essas políticas públicas são conflitantes ou projetam consensos, face aos anseios dos diversos atores sociais? A preocupação em responder a essas perguntas caminha na direção da inclusão do viés social na temática ambiental e da arenização.

É importante, na inclusão do viés social, a composição de um mínimo diagnóstico que considere os seguintes pontos: a identificação e caracterização dos intervenientes (os que afetam ou são afetados pelo "problema"); a identificação dos pontos de divergência entre a visão dos diversos intervenientes; a investigação da contribuição/influência das formulações científicas para a conceituação do problema e como isso 
interfere nas ações dos intervenientes; a verificação de "conflitos" e "consensos" entre a visão técnica e a visão dos residentes no local; a avaliação de possibilidades de ponderação; a avaliação de conflitos entre demandas de uso do solo e as possibilidades legais; etc. Todos esses tópicos requerem a aplicação de técnicas e metodologias qualitativas que consistem na busca de preceitos das ciências sociais, no resgate da oralidade e outras formas de inclusão de saberes complementares ao científico. Desse modo, acredita-se contribuir uma nova política de conhecimento e gestão da natureza e, em específico, dos areais. Cabe, ainda, salientar que a busca por novas bases teórico-metodológicas deve ser realizada sem que se percam a unidade e a identidade da Geografia, enquanto disciplina. A aproximação dos preceitos das ciências sociais é desejada, mas cabe alertar para o risco de se gerar, ou fortalecer um ramo específico da Geografia, reforçando mais ainda uma Geografia dividida em humana e física.

\section{ARENIZAÇÃO, SILVICULTURA E POLÍTICAS AMBIENTAIS NO SUDOESTE DO RIO GRANDE DO SUL}

Resumo: Desde a crise socioecológica da década de setenta do século XX, a arenização e a silvicultura vêm ocupando as pautas das questões ambientais referentes à região Sudoeste do Rio Grande do Sul, perpassando diversos segmentos da sociedade, entre comunidades locais de agricultores e pecuaristas, técnicos, cientistas e políticos. São temas inseparáveis, na medida em que a arenização é apontada como o principal processo de degradação ambiental da região, enquanto a silvicultura foi privilegiada como solução nas políticas ambientais, tanto públicas como nas parcerias do público-privado. Essas políticas apresentam conexões institucionais transescalares, do contexto global, passando pelas políticas nacionais, regionais, inclusive pelo contexto local; onde as políticas ambientais externas passam a integrar os sistemas locais de gestão agrícola e que transformam a paisagem. Os estudos realizados na localidade da Vila Kraemer, no município de São Francisco de Assis/RS, demonstram que as imagens que o Homem faz do ambiente, os valores ambientais e as preferências paisagísticas fazem parte dos mecanismos de transformação e humanização da paisagem, da criação de uma segunda natureza. Partindose dessa constatação e da premissa de que a abordagem ambiental em voga conduz a elaboração de políticas ambientais que negligenciam o viés social, propõe-se e discute-se uma "nova" abordagem, na linha da percepção ambiental, voltada para a construção de alternativas para as 
políticas de conhecimento e gestão da paisagem, com ênfase à arenização e silvicultura, que inclua o Homem enquanto sujeito.

Palavras chave: arenização - silvicultura - políticas ambientais percepção ambiental - paisagem.

\section{SANDIZATION, SILVICULTURE AND ENVIRONMENTAL POLICIES IN SOUTHWESTERN RIO GRANDE DO SUL}

Abstract: Since 1970's social-ecological crisis, sandization and silviculture have been on the environmental issues agenda in Southwestern Rio Grande do Sul, spanning various segments of society, such as local agriculturalist and rancher communities, technicians and politicians. Those are inseparable themes, given that sandization has been identified as the main process of environmental degradation in the region, whereas silviculture has been privileged as a solution in the environmental policies - both public policies, as well as public-private partnerships. Such policies present multiple scale institutional connections with the global context, going over national and regional policies and even the local context where outside policies integrate inside agricultural management systems remodeling landscape. Studies in Vila Kraemer (Rio Grande do Sul) show that the environment images that mankind makes, environmental values and landscaping preferences are part of the transformation and humanization mechanism of landscape and of creation of an analog nature. Starting from these findings and the premise that the environmental approach in vogue leads to the development of policies which neglect the social bias, we propose and discuss a so-called new approach, in line with environmental perception meaning to build alternatives fpr knowledge policies and landscape management, emphasizing sandization and silviculture, which include mankind as a subject.

Key words: sandization - silviculture - environmental policies environmental perception - landscape 


\section{BIBLIOGRAFIA}

AB'SABER, A.N. (1995) A revanche dos ventos. Derruição dos solos areníticos e formação de areais na Campanha Gaúcha. Em Ciência \& Ambiente, Universidade Federal de Santa Maria, Santa Maria, nº 11, p. 7- 31.

BATESON, G. (2000) Steps to an Ecology of Mind. Chicago University Press. $533 \mathrm{p}$.

BERED, A. R.; FERRARO, L. W.; PAGEL, S. M. (2008) Zoneamento ambiental para atividade de silvicultura. Porto Alegre: Fundação Estadual de Proteção Ambiental Henrique Luiz Hoessler. Disponível em: <http://www.fepam.rs.gov.br>. Acessada em: 10 jan. 2008.

BERTANFFY, F. et AL. (1968) General Systems theory. New York: Brazilier. 439 p.

BERTÊ, A. M. A. (2004) Problemas ambientais no Rio Grande do Sul. In: VERDUM, R.; BASSO, L. A.; SUERTEGARAY, D. M. A. (Org.). Rio Grande do Sul: paisagens e territórios em transformação. Porto Alegre: UFRGS, p. 61-70. BLEY, L. (1996) Morretes: um estudo de paisagem valorizada. In: DEL RIO, V.; OLIVEIRA, L. (Org.). Percepção ambiental: a experiência brasileira. São Paulo: Nobel; São Carlos, SP: Universidade Federal de São Carlos, p. 121-138.

CASTELLO, L. (1996) A percepção em análises ambientais. O Projeto MAB/UNESCO em Porto Alegre. In: DEL RIO, V.; OLIVEIRA, L. (Org.). Percepção ambiental: a experiência brasileira. São Paulo: Studio Nobel; São Carlos, SP: Universidade Federal de São Carlos, p. 23-38.

CORDEIRO, C. A.; SOARES, L. C. (1977) A erosão nos solos arenosos da região sudoeste do Rio Grande do Sul. Revista Brasileira de Geografia, Rio de Janeiro, vol. 39, n ${ }^{\circ}$, p. 82-150.

CUCHE, D. (1999) A noção de cultura nas ciências sociais. Bauru, EDUSC. 256 p.

DEMO, P. (2002) Introdução à Sociologia: Complexidade, Interdisciplinaridade e Desigualdade Social. São. Paulo: Atlas, 363 p.

FREITAS, E. M. (2010) Campos de solos arenosos do sudoeste do Rio Grande do Sul: aspectos florísticos e adaptativos. Tese de Doutorado. Universidade Federal do Rio Grande do Sul. Porto Alegre. $171 \mathrm{p}$.

GOLD, J. R.; BURGESS, J. (1982) Value environments. London: George Allen \& Unwin Publishers Ltd. 224 p. 
GOMES, A. M. B.; CARVALHO, C. S.; BARBOZA, V. R. D. (1990) Estudo de Geomorfologia: Alegrete, RS. Em Estudos Avançados. vol. 4, nº 9, pp. 243-254.

INGOLD, T. (2000) The Perception of the Environment: Essays on Livelihood, Dwelling and Skill.Routledge. London, 465 p.

INSTITUTO DE ESTUDOS AVANÇADOS. (1990) FLORAM. Uma Plataforma. Revista Estudos Avançados, USP. São Paulo, vol. 4, n 9, 301p.

LATOUR, B.; SCHWARTZ, C.; CHARVOLIN, F.(1998) Crises dos meios ambientes: desafios ás ciências humanas. In: ARAUJO, H. R. (Org.) Tecnociência e cultura: ensaios sobre o tempo presente. São Paulo: Estação Liberdade, p. 91125.

MATZENBACHER, Luiz Oscar. (1991) O deserto avança em Quaraí. Correio do Povo, Porto Alegre, 19 março, p. 7.

MENDONÇA, F. (2009) Geografia Socioambiental. In: ; KOZEL, S. (orgs.). Elementos de Epistemologia da Geografia Contemporânea. $1^{\text {a }}$ edição revisada, 2009, 270p: p 121-142.

MOLLER, O.; GARCIA, I.S.; GESKE, A.C.S.P.; RANZO, A.T.; ROSA, M.L. (1975) Diagóstico sobre a presença de areais na região sudoeste do Rio Grande do Sul. Porto Alegre: DRN/SUDESUL,

MONTEIRO, C. A. F. (1984) Geografia \& ambiente. Orientação, n. 5, USP, 1984, p. 19-28.

MÓSENA, M. (2006) Agricultura em áreas frágeis: as transformações decorrentes do processo de arenização em São Francisco de Assis/RS. Dissertação de Mestrado. Universidade Federal do Rio Grande do Sul. Porto Alegre, 143 p.

NASSAUER, J. I. (1995) Culture and changing landscape structure. Landscape Ecology, Amsterdam, vol. 10, n 4, p 229-237.

RIBEIRO, A. C. T. (1991) Matéria e espírito: o poder (des)organizador dos meios de comunicação. In: PIQUET, R.; RIBEIRO, A. C. T. Brasil, território da desigualdade. Rio de Janeiro: Jorge Zahar, 1991. p. 44-45.

SANTOS, M. (1997) A natureza do espaço: técnica e tempo, razão e emoção. São Paulo: HUCITEC, 308 p.

SILVA, L. A. P. (2008) Narrativas das percepções e conectividades de caminhantes nas paisagens dos areais pampeanos. Perspectivas ambientais para geração de ambiências. Dissertação de Mestrado. Universidade Federal do Rio Grande do Sul. Porto Alegre, 154 p. 
SILVICONSULT ENGENHARIA. (2007) Relatório de Impacto Ambiental Derflim Agropecuária Ltda. 80 p.

SOUTO, J. J. P. (1885) Deserto, uma ameaça? Estudo dos núcleos de desertificação na fronteira sudoeste do Rio Grande do Sul. Porto Alegre: Secretaria da Agricultura, Departamento de Recursos Naturais Renováveis, 169 p. SUERTEGARAY, D. M. A. (1987) A trajetória da natureza: um estudo geomorfológico sobre os areais do Rio Grande do Sul. São Paulo. Tese de Doutorado. 243 p.

.Desertificação: recuperação e desenvolvimento sustentável (1996) In: GUERRA, Antônio José Teixeira; CUNHA, Sandra Batista (Org.). Geomorfologia e meio ambiente. Rio de Janeiro: Bertrand Brasil, 1996. p. 249290.

; GUASSELLI, L. A.; VERDUM, R. (2001) Atlas da arenização: sudoeste do Rio Grande do Sul. Porto Alegre: Secretaria da Coordenação e Planejamento, 84 p.

VELHO, O. (2001) De Bateson a Ingold: Passos na constituição de um paradigma ecológico. Mana vol.7 n ${ }^{\mathrm{o}}$ 2. Rio de Janeiro. p. 133-140.

VERDUM, R. (2004) Depressão periférica e planalto: potencial ecológico e utilização social da natureza. In: ___ ; BASSO, L. A.; SUERTEGARAY, D. M. A. (Org.). Rio Grande do Sul: paisagens e territórios em transformação. Porto Alegre, Ed. UFRGS, p. 39-57.

VIEIRA, P. F.; BERKES, F.; SEIXAS, C. S. (2005) Gestão integrada e participativa de recursos naturais. Conceitos, métodos e experiências. APED. Florianopolis. 415 p.

WHYTE, A. (1977) Guidelines for field studies in environmental perception. Paris: UNESCO, MAB Technical Notes 5, 120 p.

Data de Submissão: 20/03/2012

Data de Aprovação: 02/02/2013 